\title{
Performance Analysis of Enhanced Interior Gateway Routing Protocol (EIGRP) Over Open Shortest Path First (OSPF) Protocol with Opnet
}

\author{
Anibrika Bright Selorm Kodzo ${ }^{1}$, \\ Koforidua \\ Polytechnic (Computer Science Dept.), \\ Christ Apostolic University College, Kumasi \\ Box 981 KF Koforidua, E/R, Ghana, W.A
}

Mustapha Adamu Mohammed ${ }^{2}$

Departemnt of Computer Science, Koforidua, Ghana, West Africa

\author{
Ashigbi Franklin Degadzor ${ }^{3}$ \\ Koforidua Polytechnic (Computer Sci. Dept.) \\ Box 981 KF Koforidua, E/R, Ghana, W.A
}

\author{
Dr. Michael Asante ${ }^{4}$, \\ Computer Science Dept., KNUST, Kumasi, Ghana, W/A \\ Contact: +233208168613
}

Abstract-Due to the increase in the easy accessibility of computers and mobile phones alike, routing has become indispensable in deciding how computes communicate especially modern computer communication networks. This paper presents performance analysis between EIGRP and OSPFP for real time applications using Optimized Network Engineering Tool (OPNET). In order to evaluate OSPF and EIGRP's performance, three network models were designed where 1st, 2nd and 3rd network models are configured respectively with OSPF, EIGRP and a combination of EIGRP and OSPF. Evaluation of the proposed routing protocols was performed based on quantitative metrics such as Convergence Time, Jitter, End-to-End delay, Throughput and Packet Loss through the simulated network models. The evaluation results showed that EIGRP protocol provides a better performance than OSPF routing protocol for real time applications. By examining the results (convergence times in particular), the results of simulating the various scenarios identified the routing protocol with the best performance for a large, realistic and scalable network.

\section{Keywords-Routing; Protocol; Algorithm; Throughput}

\section{INTRODUCTION}

The advancement in data communication technology facilitates users have easy access to services that enable users to use computers and mobile phones. Some of these services include file sharing through Bluetooth, print sharing, video streaming and voice conferencing services. The internet has created interconnected computer networks called the virtual underpinned by routing protocols. Currently the internet is playing a vital role in the life of communication networks. Data communication networks are solely based on technologies that provide the technical infrastructure base, where routing protocols transmit packets across the Internet. These routing protocols specify how routers communicate with each other by broadcasting messages. Also these routers update their routing tables based on prior knowledge of the adjacent networks that normally helps them in selecting the best routes possible between nodes that available on the network. These routing protocol differ in various like convergence, throughput, jitter delay and rout establishment

\section{RELATED WORK}

Many researchers in the past have compared the performance of these two dynamic routing protocols that is Interior Gateway Routing Protocol (EIGRP) and Open Shortest path First (OSPF), based on dissimilar parameters used the analysis. (Ittiphon et al, 2005), showed the link recovery comparison that existed between OSPF \& EIGRP and concluded based on the transmission time EIGRP is better choice than OSPF protocol whereas rerouting time after failure of a link also remains the same. (Shafiul et al, 2008), in his work explained his work on performance analysis of both EIGRP and OSPF routing protocols for real time applications including video streaming on wired and wireless networks and devices. The evaluation of these protocols based certain quantitative metrics such as Convergence Duration ,Packet Delay Variation, End to End Delay and above Throughput (Success rate of data transmitted), resulted in EIGRP performing far better than OSPF for real time video streaming and applications. Again (Sheela and Thorenoor, 2001), presented some implementation decisions on protocols that involved either distance vector protocols or link state protocols or even both and compared these protocols using different parameters. Finally it has proven from the results shown that EIGRP utilizes a far better network convergence time, with less bandwidth requirements and as well as efficient CPU and memory utilization when it is compared with other routing protocols like Open Shortest Path First Protocol (OSPFP) which is a link state routing protocol. This paper tested the two protocols on the basis of E-mail upload response time and Hypertext Transfer Protocol (HTTP) page response time, for different number of workstations (Holmes et al, 2002).

\section{A. Objectives}

- To simulate OSPF protocol and EIGRP protocol using OPNET based on two quantitative metrics (Throughput and Packet Delay Variation).

- Analyze the results of simulation. 
- To determine a suitable and appropriate protocol for a scalable network.

\section{B. Background Theory}

In IP networks, a routing protocol usually carries packets by transferring them between different nodes. When considering a network, routing takes place hop by hop. Routing protocols have the following objectives:

- To establish communication among routers

- To construct routing tables based on routing loops

- To make routing decisions

- To learn existing and alternate routes

- To distributed information amongst autonomous neighbouring routers.

Routers perform routing by interconnecting several autonomous networks and routing packets through alternate routes and forwarding packets to different several networks based routing algorithms. The cardinal function behind routing protocols is designed to establish the best and alternate path from the source router to the destination router. A routing algorithm operate by employs several metrics, which are employed to resolve the best route that can be used to get to a network in which case this can be achieved through the use of a single or several properties of the path. For conventional routing protocols, networks are classified as Link State Routing Protocols and Distance Vector Routing Protocols. The conventional routing protocol is usually used for other types of communication networks such as Wireless Ad-Hoc Networks, Wireless Mesh Networks etc (Billings et al, 2002). Neighbor Discovery occurs by sending HELLO packets at intervals with a comparatively low overhead. After receiving a HELLO packet from its neighbors, the router ensures that its neighboring routers are active and that exchange of routing information will be possible. In the determination of the best path for transmission some specific metrics such as speed, node delay, congestion, and interference were used. OSPF is a type of routing algorithm that uses bandwidth as a routing metric while RIP (Routing Information Protocol) employs hop count whereas EIGRP uses a combination of bandwidth and delay as routing metrics.

\section{Metric Parameters}

In the case routing metric is measured in a manner to select the best and alternate routes as a means of ranking the routing protocol from most preferred to least preferred. In the case of routing, different metrics were employed for the purpose of different routing protocols. In the Internet Protocol routing, (Internet Protocol) routing protocols, below are some of the following routing metrics are used mostly:

- Hop count: It is used to determine the number of routers that are allowed to traverse the best route in a network in order to reach the desired destination.

- Bandwidth: Also a bandwidth metric is used to determine its routing path based on the best bandwidth speed possible.
- Delay: Delay is a measurement metric that specifies time for a packet to pass through a path. Delay depends on some factors, such as link bandwidth, utilization, physical distance travelled and port queues.

- Cost: It is the duty of the network administrator or Internet Operating System (IOS) engineer to determine the cost by specifying the best and alternate route to a destination. The cost of the routing metric can be used to represented either as a metric or a combination of metrics.

- Load: It is described as the traffic utilization of a defined link. The routing protocol use load in the calculation of a best route.

- Reliability: Reliability is used to determine the efficiency of the network as well as, it calculates the link failure probability and it can be calculated from earlier failures or interface error count (Douglas et al, 2006).

\section{Routing Methodologies}

A router is responsible for accomplishing the following procedure:

- Router are able to learn about directly connected networks and its own links.

- A router must have a connection with its directly connected and adjacent networks and this performed by the help of HELLO packet exchanges.

- Routers must send what are called a link state packet which contains the state of the available links.

- A router is able to stores a link state packet copy which is received by its neighbouring routers.

- A router must also independently establish the least cost path for the topology as proposed by (Lammle et al., 2005).

\section{Methodology}

During the implementation of a real world model of the simulation system that is designed by OPNET, a suitable algorithm was also adhered following the design using the packet simulator. Figure 3.1 shows a flow chart of the steps.

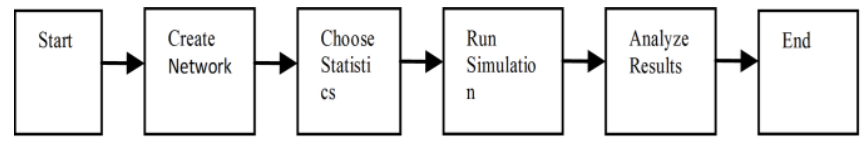

Fig. 1. Simulation in OPNET flow chart and Design Steps

\section{OPNET Simulator}

OPNET is a type of network simulator that stands for Optimized Network Engineering Tools modeler 14.0 was would be used as the network simulation environment. OPNET is a simulator built on top of Discrete Event System (DES) and also it is used to simulates the system functional characteristics and behavior often by modeling each event and process in the system by the help of user defined 
functionalities. OPNET is also suitable for the simulation of heterogeneous network coupled varying protocols.

\section{The Anatomy of OPNET (Simulation Software)}

OPNET is a high level discrete event simulator with striking user interface that is was developed by the $\mathrm{C}$ and $\mathrm{C}+$ + programming languages with their source codes.

\section{A. Hierarchical Structure of OPNET Model}

The OPNET simulator has three major functional models. These are:

\section{B. Network Domain Model}

The Network Domain Model has three sections. These are: Physical connection, interconnection and configuration. It is meant represent all system attributes like as network, subnetwork on the geographical map to be simulated.

\section{Node Domain Model}

The Node domain is used to constitute all internal infrastructure of the network domain. Nodes can be routers, workstations, satellite as well

\section{Process Domain Model}

The Process domain are used to normally specify the intrinsic attributes of the processor and queue models by the use of use of source code $\mathrm{C}$ and $\mathrm{C}++$ libraries which is inside the node models as indicated above.

\section{E. Measurements Characteristics}

This section actually talks about measurement specifications, measurements that relate to the performance metrics specifically Throughput and Packet Delay Variation are done from the acquired results of Discrete Event Simulation in figure 3.6.Detailed information about the simulation and measurements are explained further below based on the various models created.

Network Topology under simulation

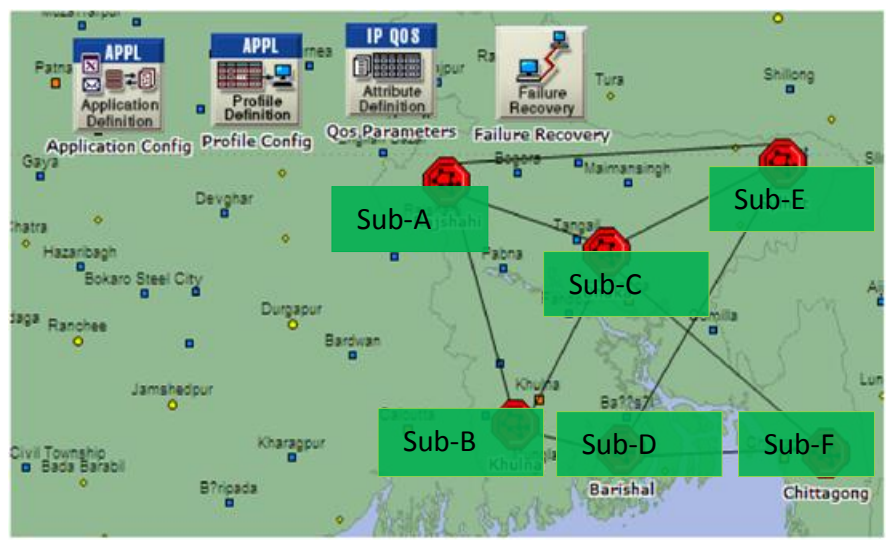

Fig. 2. The proposed network under simulation

In this thesis, three scenarios EIGRP, OSPF and EIGRP_OSPF were created that consists of six interconnected subnets where routers within each subnet are configured by using EIGRP and OSPF routing protocols. The network topology composed of the following network devices and configuration utilities:
$>$ Switches

> CS_7200 Cisco Routers

$>$ Ethernet Server

> PPP_DS3 Duplex Link

> PPP_DS1 Duplex Link

$>$ Ethernet 10 BaseT Duplex Link

$>$ Ethernet Workstation

$>$ Six Subnets

$>$ Application Configuration

$>$ Profile Configuration

$>$ Failure Recovery Configuration

$>$ QoS (Quality of Service) Attribute Configuration

The network topology designed using OPNET as shown in figure3.6. Six subnets that are interconnected to each other were considered. All of the subnets contain routers, switches and workstations. An Application Definition Object and a Profile Definition Object have all been named correspondingly the figure 3.6. Application Config and Profile Config in the figure 3.6 are added from the object palette into the workspace. The Application Config allows generating different types of application traffic. As far as real time applications are concerned in this thesis, the Application Definition Object is set to support Video Streaming (Light) and Voice Conferencing. A Profile Definition Object defines the profiles within the defined application traffic of the Application Definition Objects. Weighted Fair Queuing (WFQ) is a scheduling technique that allows different scheduling priorities on the basis of Type of Service (ToS) and Differentiated Service Code Point (DSCP).The routers are connected using PPP_DS3 duplex link with each other. The switches are connected to routers using same duplex link. Ethernet workstations are connected to switch using 10 Base T duplex links and also links speeds of $44.76 \mathrm{Mbps}$ for the first set of subnet connection with link type of PPP_DS3 and 1.544 Mbps for the second set of subnet connection with a link type of PPP_DS1 deployment to ensure standard data transmission across the links. The same numbers of bits were sent simulated for the various scenarios (EIGRP, OSPF, and EIGRP_OSPF). In this simulation three network models were created, simulated and measurements were carried out based on two performance metrics that is Throughput and Packet Delay Variation.

"Three network models were simulated, which are configured and run as 1st scenario with OSPF alone, 2nd one with EIGRP alone and 3rd one with both EIGRP and OSPF concurrently".

Three network models were simulated, which are configured and run as 1st scenario with OSPF alone, 2nd one with EIGRP alone and 3rd one with both EIGRP and OSPF concurrently. One failure link between Sub-E and Sub-D has been configured to occur at 300 seconds and to recover at 500 seconds. The links that have been used in these scenarios are given in Table 1.0 below. 
TABLE I.

LINK CONNECTION

\begin{tabular}{|c|c|c|}
\hline Link Type & $\begin{array}{l}\text { Connection between } \\
\text { subnets }\end{array}$ & Link Speed \\
\hline PPPDS3 & $\begin{array}{l}\text { Sub-C<->Sub-F, Sub- } \\
\text { A }<->\text { Sub-C } \\
\text { Sub-E<->Sub-C, Sub- } \\
\text { B }<->\text { Sub-C } \\
\text { Sub-E<->Sub-D, Sub- } \\
\text { B }<->\text { Sub-D }\end{array}$ & $44.736 \mathrm{Mbps}$ \\
\hline PPPDS1 & $\begin{array}{l}\text { Sub-A }<->\text { Sub-E ,Sub- } \\
\text { B }<->\text { Sub-A Sub-C }<- \\
>\text { Sub-F }\end{array}$ & $1.544 \mathrm{Mbps}$ \\
\hline
\end{tabular}

F. Results of simulation for the three models

TABLE II. PACKET DELAY VARIATION RESULTS FOR EIGRP

\begin{tabular}{llll}
\hline $\begin{array}{l}\text { No. of } \\
\text { bits } \\
\text { sent }\end{array}$ & $\begin{array}{l}\text { Scenario } \\
\text { Name }\end{array}$ & $\begin{array}{l}\text { Routing } \\
\text { Protocol }\end{array}$ & Packet Delay (sec) \\
\hline $\mathbf{5}$ & EIGRP & EIGRP & 0.026 \\
$\mathbf{1 0}$ & EIGRP & EIGRP & 0.028 \\
$\mathbf{1 5}$ & EIGRP & EIGRP & 0.030 \\
$\mathbf{2 0}$ & EIGRP & EIGRP & 0.032 \\
\hline
\end{tabular}

TABLE III.

PACKeT DELAY VARIATION RESULTS FOR OSPF SCENARIO

\begin{tabular}{llll}
\hline $\begin{array}{l}\text { No. of } \\
\text { bits sent }\end{array}$ & $\begin{array}{l}\text { Scenario } \\
\text { Name }\end{array}$ & $\begin{array}{l}\text { Routing } \\
\text { Protocol }\end{array}$ & $\begin{array}{l}\text { Packet Delay } \\
\text { (sec) }\end{array}$ \\
\hline $\mathbf{5}$ & OSPF & OSPF & 0.043 \\
$\mathbf{1 0}$ & OSPF & OSPF & 0.045 \\
$\mathbf{1 5}$ & OSPF & OSPF & 0.047 \\
$\mathbf{2 0}$ & OSPF & OSPF & 0.049 \\
\hline
\end{tabular}

TABLE IV. PACKET DELAY VARIATION RESULTS FOR EIGRP_OSPF SCENARIO

\begin{tabular}{llll}
\hline $\begin{array}{l}\text { No. of bits } \\
\text { sent }\end{array}$ & $\begin{array}{l}\text { Scenario } \\
\text { Name }\end{array}$ & $\begin{array}{l}\text { Routing } \\
\text { Protocol }\end{array}$ & $\begin{array}{l}\text { Throughput } \\
(\mathrm{msec})\end{array}$ \\
\hline $\mathbf{5}$ & EIGRP_OSPF & $\begin{array}{l}\text { EIGRP and } \\
\text { OSPF }\end{array}$ & $8,50,000$ \\
$\mathbf{1 0}$ & EIGRP_OSPF & $\begin{array}{l}\text { EIGRP and } \\
\text { OSPF }\end{array}$ & $8,82,000$ \\
$\mathbf{1 5}$ & EIGRP_OSPF & $\begin{array}{l}\text { EIGRP and } \\
\text { OSPF }\end{array}$ & $8,55,000$ \\
$\mathbf{2 0}$ & EIGRP_OSPF & $\begin{array}{l}\text { EIGRP and } \\
\text { OSPF }\end{array}$ & $8,57,000$ \\
\hline
\end{tabular}

TABLE V. THROUGHPUT SIMULATION RESULTS FOR EIGRP

\begin{tabular}{llll}
\hline No. of bits sent & Scenario Name & Routing Protocol & $\begin{array}{l}\text { Throughpu } \\
\mathbf{t} \\
\text { (bits/sec) }\end{array}$ \\
\hline 5 & EIRGP & EIGRP & $8,80,000$ \\
10 & EIRGP & EIGRP & $8,20,000$ \\
& & & \\
15 & EIRGP & EIRGP & $8,85,000$ \\
20 & EIGRP & EIRGP & $8,87,000$ \\
\hline
\end{tabular}

TABLE VI. THROUGHPUT SIMULATION RESULTS FOR EIGRP_OSPF

\begin{tabular}{llll}
\hline $\begin{array}{l}\text { No. of bits } \\
\text { sent }\end{array}$ & $\begin{array}{l}\text { Scenario } \\
\text { Name }\end{array}$ & $\begin{array}{l}\text { Routing } \\
\text { Protocol }\end{array}$ & $\begin{array}{l}\text { Packet } \\
\text { Delay } \\
\text { (msec) }\end{array}$ \\
\hline $\mathbf{5}$ & EIGRP_OSPF & EIGRP and OSPF & 0.026 \\
$\mathbf{1 0}$ & EIGRP_OSPF & EIGRP and OSPF & 0.027 \\
$\mathbf{1 5}$ & EIGRP_OSPF & EIGRP and OSPF & 0.028 \\
$\mathbf{2 0}$ & EIGRP_OSPF & EIGRP and OSPF & 0.029 \\
\hline
\end{tabular}

\section{RESULTS AND FINDINGS}

\section{A. Introduction}

In this section, the results obtained in chapter three are presented with their Performance Analysis of Enhance Interior Gateway Routing Protocol over Open Shortest Path First protocol. In all a model of three networks were designed and simulated, with configuration parameters and simulated based on 1st scenario with OSPF alone, 2nd scenario with EIGRP alone and 3rd scenario was a combination of both EIGRP and OSPF concurrently. A failure link established between Sub-E and Sub-D has been configured to occur at 300 seconds and to recover at 500 seconds tentatively.

\section{B. Packet delay variation graph}

Packet Delay Variation is measured based on the difference in the delay of the packets arriving at the destination. This performance and measurement metric has huge influence on the video and voice applications especially during streaming. The below figure 3.0, is the linear time variation increases starting from bits 5 to bits 20 showing that with the increase in traffic for voice and video applications the delay in packet transmission increase and EIGRP is slow to resolve packet delays when there is network congestion, and this also results in broken packet sizes before arriving at the destination, poor error detection and correction mechanisms and also poor bit synchronization may be the possible causes.

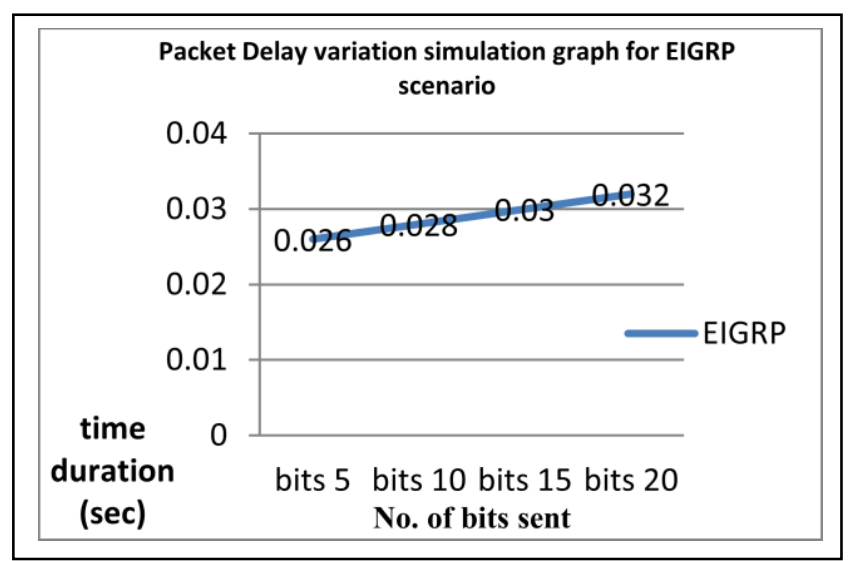

Fig. 3. Packet delay variation graph

\section{Throughput simulation graph}

The throughput is a key parameter to determine the rate at which total data packets are successfully delivered through the 
channel in the network. Figure 4.0 indicates that, bits 20 have high throughput and less packet loss than bits 5, bits 10 and bits 15 respectively. This means that EIGRP is efficient in handling throughput and packet loss during network congestion periods and therefore leads better error detection and correction, bit synchronization and faster routing table update interval time by EIGRP. Find below figure 4.0

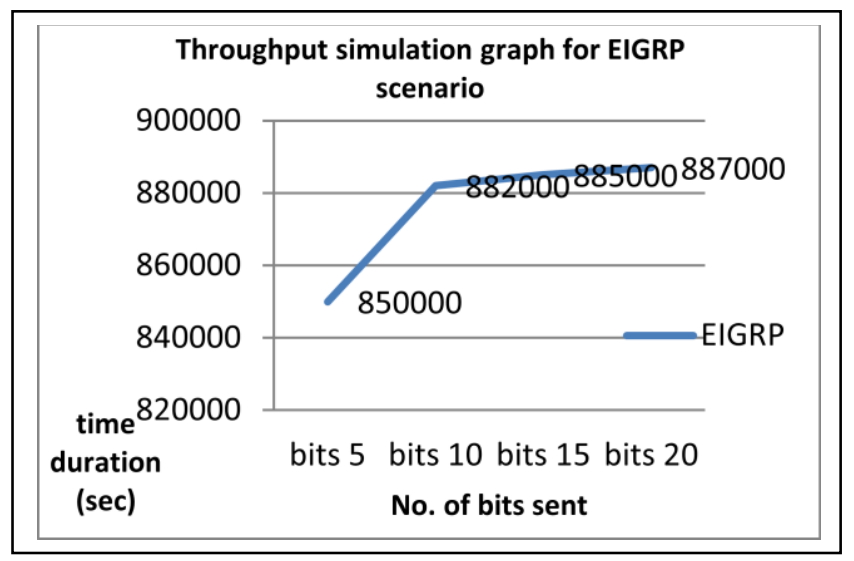

Fig. 4. Throughput simulation EIRGP

\section{Packet delay simulation graph}

This metric has huge influence on the manners of video applications. It is observed from the figure 5.0 that, the packet delay variation for OSPF networks are having higher values especially for that of bits 20 when it was sent through the OSPF network. Due to this, OSPF used triggered updates that allow efficient use of bandwidth and faster convergence time and not as susceptible to routing loops as EIGRP but requires more memory and processing power and harder to configure than EIGRP.

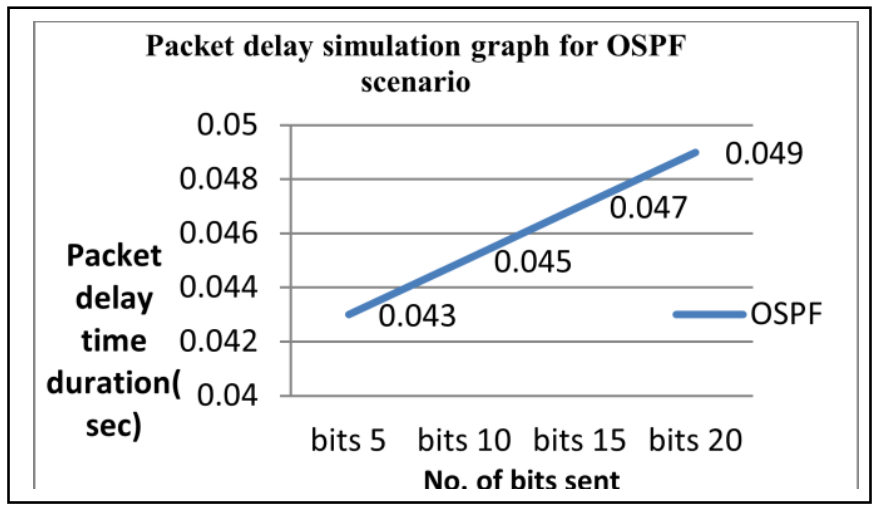

Fig. 5. Packet Delay simulation graph for OSPF protocol

\section{Packet delay simulation graph for EIGRP_OSPF scenario}

Packet Delay variation is measured by the difference in the delay of the packets. This metric has huge influence on the manners of video applications. It is observed from the figure 6.0 that EIGRP_OSPF has less packet delay variation than EIGRP and OSPF networks. Apparently, Figure 6.0 shown that despite of high congestion in the network, EIGR_POSPF is much better than OSPF and EIGRP network protocols in terms of packet delay variation and ensures efficient packet delivery.

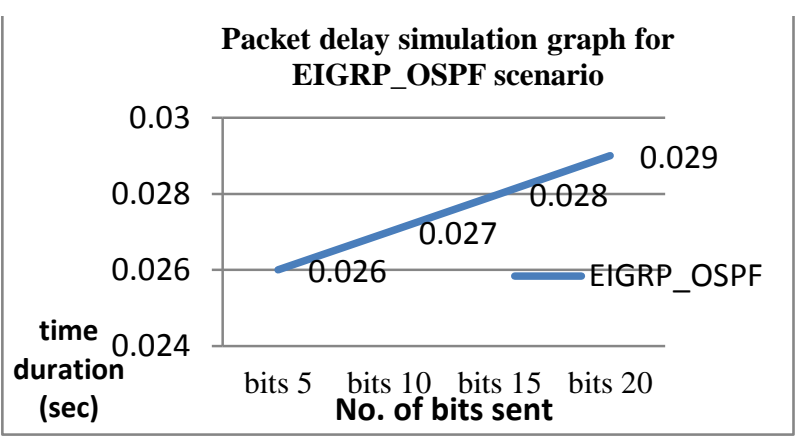

Fig. 6. Packet delay simulation EIGRP_OSPF

\section{Throughput simulation graph for EIGRP_OSPF}

The throughput is a key parameter to determine the rate at which total data packets are successfully delivered through the channel in the network. Figure 7.0 below indicates that El GRP_OSPF has higher throughput and less packet loss than OSPF and ElGRP networks especially for bits 15 and 20 respectively indicating an efficient network performance protocol suitable for voice and video applications .In effect EIGRP_OSPF has a better mechanism to ensure faster convergence and high throughput during data transmission especially where network congestion is rampant.

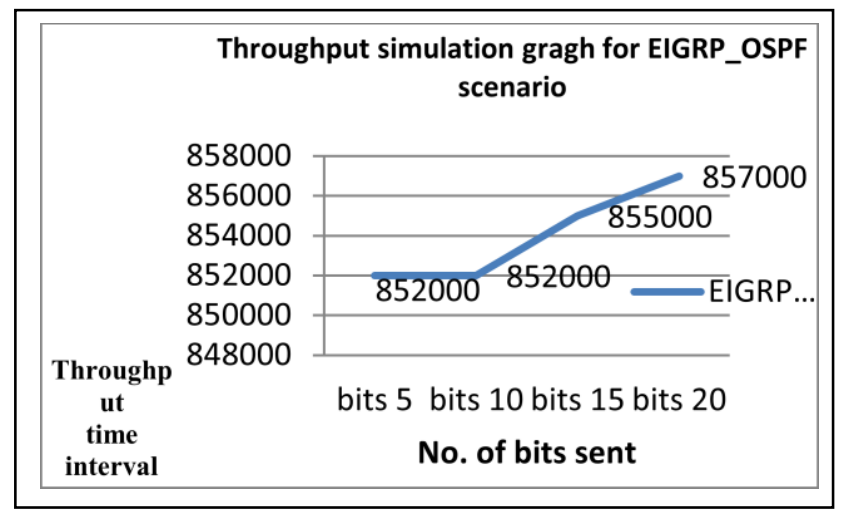

Fig. 7. Throughput simulation graph for EIGRP_OSPF

\section{CONCLUSION/RECOMMENDATIONS}

Network scalability is very important as it allows for future expansion of the network infrastructure can be enhanced by reducing network congestion and this demonstrates that the network convergence time is far better of as compared to EIGRP_OSPF and OSPF networks because EIGRP network is able learn the topological information and updates the routing table faster especially EIGRP and OSPF are widely being used in the computer networking. In this research work, I have presented a per analysis of selected routing protocols such as EIGRP, OSPF and the combination of EIGRP and OSPF

The result of the simulation has shown the difference between 
the end to end delay of EIGRP_OSPF network is relatively less than EIGRP and OSPF networks. As a result unstable network bandwidth, data packets in EIGRP_OSPF network reach faster to their destination as compared to OSPF. Another performance metrics for real time applications is packet delay variation that is a measurement of the difference between the delays of packets on transmission. The performance of packet delay variation for EIGRP_OSPF scenario is far better than OSPF and EIGRP relatively. Also, concerning the packet delay variations of EIGRP and OSPF networks is high while EIGRP_OSPF network is low. The case in the of context of packet loss, it was found that the packet loss in the EIGRP_OSPF network is less than OSPF and EIGRP networks. In final comparison, the overall simulation results have reflected that the maximum throughput in the combination of EIGRP and OSPF network is much higher than OSPF and EIGRP networks. In this research, the performance analysis among EIGRP, OSPF and combination of EIGRP and OSPF routing protocols for real time applications have been analyzed sequentially. By comparing comparing these protocols' performances, it can also be concluded that the combined implementation of EIGRP and OSPF routing protocols used in the network scenario performs far better than OSPF and EIGRP.

\section{REFERENCES}

[1] Christian Huitema, "Routing in the internet" 2. Ed. Prentice Hall PTR, cop. 2000.

[2] Cisco, "Internet Technology Handbook" ,2009

[3] Cisco, "IP Routing, Introduction to EIGRP" Document 1 D: 13669.

[4] Douglas E. Comer, 2006.

[5] Esuendale Lemm, Syed Hussain, WendwossenAnjelo 2010.

[6] FarazShamim, Zaheer Aziz, Johnson Liu, Abe Martey, 2002.

[7] J. Broch, D. Maltz, D. Johnson, Y. Hu and, 1998.

[8] K. Yamazaki and K. Sezaki, 2002.

[9] S. Basagni, I. Chlantac, V. Syrotiuk and B. Woodward, 1998.

[10] W. Su, S-J. Lee and M. Gerla, 2003.

[11] Y. Bae and N. Vaida, 1998. 